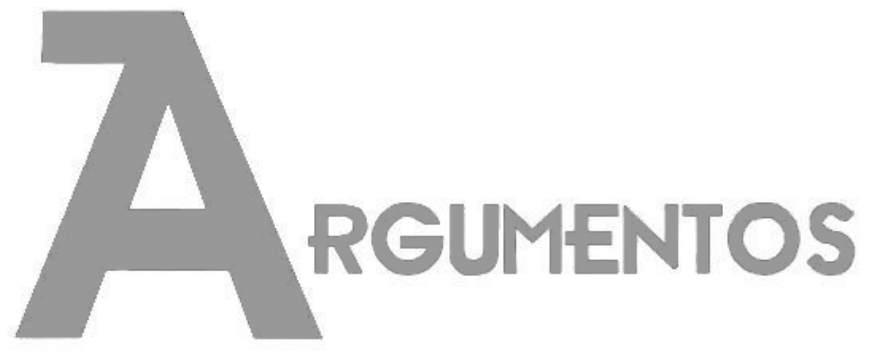

Vol. 16, n. 2, jul./dez. 2019 ISSN: 2527-2551 (online)

http://www.periodicos.unimontes.br/argumentos

Resenha

ALATAS, Syed Farid; SINHA, Vineeta. Sociological Theory Beyond the Canon. Singapura: Palgrave Macmillan, 2017.

\title{
Da pretensão generalista das ciências para a denúncia do colonialismo: a proposta de um universalismo pluralista na teoria social
}

Daliana Antonio ${ }^{1}$

Recebido em: 11/05/2019

Aprovado em: 26/08/2019

Resumo: A obra resenhada resulta do reconhecimento da trajetória intelectual de Syed Farid Alatas e Vineeta Sinha, dedicada em análises sobre a colonização e a descolonização. Afirmam que a teoria social, verificados os currículos de cursos de formação em diferentes universidades ao longo da história da humanidade, desprezaram, quando não muito, impediram o conhecimento sobre produções não ocidentais, somada a invisibilidade das produções de mulheres. Sob tendências ao Eurocentrismo e ao Androcentrismo, teorias sociais que vieram a ser denominadas canônicas devido à esse poder de espraiamento acadêmico, promoveram uma hegemonia da idéia de civilização. Destacam que o modo de produção capitalista, sendo comumente estudado a partir das análises do contexto europeu, ao invés de "capitalismo industrial" poderia ter sido denominado "capitalismo colonial", já que tal desenvolvimento somente foi possível via um processo colonizatório. Entretanto, mesmo que tenha havido produções de pesquisas sobre "outros" olhares, as denominações a partir do olhar do colonizador ainda são hegemônicas, visto a própria denominação "não ocidental" que contribui na institucionalização dos cânones. Para ambos, não se trata de um problema ensinar os cânones, mas reproduzir como se faz na Europa, observados os programas das pós-graduações da Ásia e África. Nesse sentido, a obra sintetiza negligências já discutidas por pensadoras/es africanas/os, tais quais Paulin J. Hountondji (1997), Akinsola Akiwowo (1999) e Oyèrónkẹ

\footnotetext{
1 Doutoranda em Sociologia pela Universidade de Brasília (UnB), Brasil, professora da Universidade Estadual de Montes Claros (Unimontes), Brasil, bolsista com apoio da Fundação de Amparo à Pesquisa de Minas Gerais (FAPEMIG), Brasil. E-mail: daliana.antonio@unimontes.br. ORCID: https://orcid.org/00000002-2492-8837.
} 
Oyèwùmí (2011), por exemplo, e proporciona uma reflexão "mestiça” (Glória Anzáldua, 2016) que reconheça as "teorias do sul" (Raewyn Connel, 2007).

Palavras-chave: cânones, teoria sociológica, colonialismo, eurocentrismo, androcentrismo.

O texto de Syed Farid Alatas e Vineeta Sinha apresenta pensadoras/es não europeus que foram negligenciados ou marginalizados diante do potencial teóricometodológico de seus escritos. Os autores defendem uma universalidade teórica da Sociologia que não deve estar limitada aos teóricos considerados canônicos, tais quais Karl Marx, Émile Durkheim e Max Weber. Objetivam, ainda, criticar o enquadramento dos não europeus como orientalistas, pós-colonialistas ou como precursores de uma sociologia endógena, por alguns denominada "indígena". Ademais, apontam como pressupostos civilizacionais "modernos" incitaram uma ciência universal, em nome do "progresso" da humanidade, negligenciando pensamentos que acionavam questões étnicorraciais e de gênero nas práticas colonizatórias. O que hoje se constata como eurocêntrico e androcêntrico nas ciências esteve presente nos escritos das/os pensadoras/es não ocidentais e, por isso, a obra em questão é enquadrada no debate que intenta a emergência de uma teoria global e demanda a reconstituição de uma história dos processos colonizatórios. Como afirmou Raewyn Connel (2007) sobre as teorias "do sul", a proposta de uma nova historiografia é imprescindível para uma reconstituição teórica em Sociologia.

O livro se estrutura com uma introdução sobre o eurocentrismo e o androcentrismo na teoria sociológica e prossegue, nesta ordem, com uma síntese sobre as/os seguintes pensadoras/es: Ibn Khaldun (1332-1406), Karl Marx (1818-1883), Harriet Martineau (1802-1876), Max Weber (1864-1920), José Rizal (1861-1896), Émile Durkheim (1858-1917), Said Nursi (1877-1960), Pandita Ramabai Saraswati (1858-1922), Florence Nithingale (1820-1910) e Benoy Kumar Sarkar (1887-1949), encerrando com um epílogo resgatando os objetivos desta coletânea. Boa parte do pensamento sintetizado na obra se centra na crítica da imposição das regras imperialistas que eliminaram outras formas de "progredir", sendo que os conhecimentos sociológicos mediaram o processo de legitimação das políticas colonizatórias no contexto da formação de Estados-nação. Constatam a persistência de preconceitos por meio do eurocentrismo e do androcentrismo ao negar o reconhecimento de pensamentos e 
idéias não ocidentais na formação da teoria social, quando não muito a negligência de pressupostos teórico-metodológicos de pensadoras/es não ocidentais.

Como se pode ver na lista supracitada, os cânones "pais fundadores" da sociologia, Marx, Durkheim e Weber, não foram retirados desta coletânea, pois a proposta de Alatas e Sinha não se trata de "jogar o bebê com a água do banho", mas propor uma nova leitura que reconheça que as perspectivas eurocêntrica e androcêntrica limitaram conceitos e todo um aparato teórico-metodológico no exercício de generalização em Sociologia. Por isso, a introdução do livro se dedica à crítica da modernidade, constituição esta estabelecida na Europa como originária e centro de produção de conhecimentos ditos racionais. Daí, destacam a posicionalidade na apres entação das/os pensadoras/es em questão, particularmente sobre os fundamentos religiosos que explicam suas filiações teóricas e ambição científica. Deste modo, apontam como principal problema da categoria moderna o encerramento de díades comparativas e hierárquicas, sempre relativas ao irracional, que tendem a não reconhecer certas práticas, tais como as religiosas, na "produção" da razão. Deste modo, a articulação razão e emoção para a constituição da díade cultura e natureza, por exemplo, legitimou a que territórios e corpos fossem objetos no exercício de dominação e controle da natureza e do trabalho humano, bem como de seus recursos e produtos materiais e simbólicos (QUIJANO, 2005). O texto é, assim, uma advertência da não contextualização sobre os aspectos colonizatórios nas teorias sociais ditas clássicas. A expansão da formação intelectual foi, de certo modo, universalizada, e potencializou a reprodução desses aspectos, como "revelada" nas análises empíricas e nas políticas estatais de territórios e corpos colonizados.

O primeiro pensador, Ibn Khaldun, apresentado por Alatas, viveu no século XIV. Se dedicou a estudar as tradições islâmicas na constituição da história e da filosofia de modo a identificar aspectos cíclicos nas sociedades. Analisou as diferenças entre os fatores que orientam modos de vida, ocupação, coesão social, relações de poder, desenvolvimento de ofícios, em sociedades nômades e sedentárias. Ocupou-se na pesquisa sobre as origens e as causas dos fatores que diferenciam tais sociedades, não no intuito de normatizar de modo linear e progressivo, mas na positividade destes processos. Ou seja, para Khaldun, as narrativas sobre a formação de grupos sociais acionaram uma explicação positiva sobre a formação do estado. Khaldun constrói uma 
teoria do estado que está estreitamente vinculada às análises da reforma religiosa, uma vez que foram movimentos religiosos que impulsionaram funções sociais. Para o pensador, as pessoas passaram a ter um sentimento de grupo em razão do estabelecimento e da importância do cumprimento de serviços administrativos por meio do estado e afirma que questões de classe e etnicidade são inerentes às questões religiosas.

O segundo capítulo trata de Karl Marx e Alatas destaca como as considerações religiosas foram contrapostas ao cerne teórico, que tem nas concepções materialistas da história a base evolucionária das relações sociais de produção da vida material para a existência humana. A religiosidade seria uma condição transicional, caracterizadas no modo anterior ao feudalismo, qual seja, o modo de produção asiático, e limitadas às estagnações sustentadas religiosamente. Daí, o autor avalia a perspectiva da destruição e regeneração que se deu em nome do marxismo na missão do colonialismo britânico, de modo a legitimar a exploraçãovia estado e a imposição das regras da classe capitalista sobre a classe trabalhadora.

Já o terceiro capítulo é escrito por Vineeta Sinha e dedicado à Harriet Martineau sendo, principalmente, destacado o caráter androcêntrico que justificou a invisibilidade de seus escritos. O que não afrontaria os papéis sociais hierarquizados de homens e mulheres, já que a preocupação positivista ${ }^{2}$ de Martineau se dava a respeito da moralidade, das práticas e atitudes normativas que garantissema sistematização, por meio das instituições, desses papéis. A principal preocupação de Martineau era a não participação de mulheres no sistema educacional. Para ela, o progresso somente se garantiria por meio da educação feminina voltada para o melhor modo de desenvolver habilidades específicas, no caso, a maternidade e os cuidados como responsabilidade de mulheres. Destacada a importância dos seus escritos sobre os Estados Unidos, por conter qualidade descritiva tão relevante quanto à famosa obra de Alexis de Tocqueville, somadas análises sobre raça, gênero e classe, Martineau identificou as discrepâncias entre princípios democráticos e práticas sociais. Assim, identificou preconceitos e discriminações institucionalizadas na teoria democrática que impediram a autonomia

\footnotetext{
2 Harriet Martineau traduziu os textos de Auguste Comte auxiliando na propagação dos ideais positivistas para a descoberta de leis da sociedade. Seu olhar se limitada às mulheres burguesas, sujeitadas à ociosidade no âmbito doméstico quando cessava o período dos cuidados com as crianças.
} 
individual. Para Martineau, os princípios morais democráticos sãofundamentais para a felicidade e, sendo uma condição humana universal, já que bem de Deus, seria a única garantia para o progresso moral.

No próximo capítulo, Alatas fala de Max Weber e o caráter eurocêntrico na sua correspondência da ética com o desenvolvimento econômico, de modo a associar a burocratização à racionalidade formal proporcionada por esta ética. Assim, a acumulação de capital passa a ser um sinal da graça de Deus sob uma ética ascética e não religiosa, donde as sociedades capitalistas modernas passam a ser caracterizadas por ações orientadas sob normas vinculadas à esta ética. Para Weber, a racionalização formal da vida é uma vida desencantada e entender o mundo é dessacralizá-lo. Uma tipificação das ações foi demonstrada numa hierarquia definida em termos de respectivas esferas de competência, no caso das modernas sociedades capitalistas, instaurada na burocracia, que fixa regras de modo a criar uma jurisdição que invade todas as esferas da vida.

No capítulo sobre José Rizal, Alatas afirma o caráter colonizatório da racionalidade sobre os filipinos. Rizal foi o primeiro pensador filipino que sistematizou questões sociais e políticas para a constituição de uma teoria da sociedade colonial. As regras coloniais espanholas se sustentavam no discurso sobre a indolência dos filipinos. Para Rizal, a causa da indolência deve ser explicada a partir das regras da sociedade colonial, que falharam na modernização da Filipinas por seu caráter impositivo e opressor. Três aspectos foram substanciais: a visão sobre a natureza e as condições da sociedade colonial, a crítica ao conhecimento colonial produzido sobre Filipinas e a discussão sobre o significado e o requerimento da emancipação nacional. $O$ atraso e a indolência foram resultantes da corrupção do governo colonial e da legitimidade das narrativas da Igreja Católica. Foram atitudes hipócritas e cruéis a justificar a colonização. A sociedade filipina era relativamente avançada antes da colonização espanhola, mas houve um apagamento da memória e sobrevaleceu relatórios errôneos e depreciativos feitos por espanhóis. Logo, há um mito da indolência associada ao clima tropical e ao trabalho. O que exige uma reinterpretação da história colonial, destacando o extermínio indígena, o declínio das formas agricultáveis e o apagamento dos conhecimentos sobre a terra, a pecuária e o artesanato. Dada a inferiorização de trabalhos manuais, o que fez com que produtos filipinos deixassem de ser demandados, a colonização incentivou a 
participação em cerimônias religiosas que demandavam turnos inteiros de dedicação à uma única esperança: o reino dos céus. Segundo Rizal, anteriormente, o amor religioso fomentava o auto-amor, de modo que as pessoas tinham seus próprios julgamentos, mas a moralidade colonizatória da Igreja Católica impôs rituais e superstições destrutivos. As ações e os escritos de José Rizal foram considerados revolucionários e passíveis da atribuíção de traição contra a Espanha. Assim foi acusado e condenado à execução.

O sexto capítulo é dedicado a Emile Durkheim e Sinha destaca o compromisso com o projeto positivista, de certo modo, obnubilado em sua proposta metodológica. Como se sabe, há uma agenda nas "regras do método sociológico" para a autonomia de um campo científico, regulada na noção de solidariedade em prol de uma ordem social que demandava solidariedade e moralidade afins à modernidade. Sinha destaca o caráter reformista da teoria de Durkheim, tendo implícitas muitas prescrições normativas nos seus principais escritos que trataram sobre a organização do trabalho no processo de industrialização, sobre as formas religiosas e sobre o suicídio. Deste modo, o eurocentrismo do pensamento de Durkheim persuadiu políticos, educadores, administradores universitários e burocratas para o cumprimento de uma agenda sob a perspectiva de método científico.

No sétimo capítulo, Alatas escreve sobre o teólogo e pensador otomano Said Nursi que se dedicou à discussão sobre o sectarismo promovido durante a "modernização" da Turquia. É sabido que o republicanismo na Turquia provocou a cisão típica da secularização do estado, mas também o sectarismo de grupos religiosos, num país predominantemente muçulmano. Aquém à alienação e à anomia, Alatas destaca a questão do desespero que acometeu essa transição modernizante da sociedade por meio das políticas seculares do Estado. O problema central desse processo civilizacional foi a dessacralização. Seu pensamento atribuiu à teologia uma forte dimensão sociológica, de modo a criticar a separação do islamismo como política e do islamismo como fé. Para Nursi, uma teologia social é política e, por isso, é uma proposta de reforma da sociedade muçulmana que considere a fé no islã. A modernidade, para ele, implicaria na demonstração das verdades das crenças religiosas sobre a existência de Deus, sobre as profecias, a ressurreição, a justiça etc. Entretando, fortalecer essas crenças evitaria as patologias da modernidade, tais quais a infelicidade, o desespero, os dualismos e o isolacionismo. Apesar de não desconsiderar a competição como uma característica 
humana, aponta o problema da oposição de certos modos de vida sobre outros como o fator produtor de injustiças. Sua concepção de justiça está vinculada à uma teodicéia a instruir a justiça dos humanos. Sendo assim, o problema não é a falta de justiça, mas a falta de fé. Nursi criticou a civilização moderna, predominantemente centrada na Europa, sob princípios assentados no cristianismo e na filosofia do naturalismo. O pensador sugere que o islamismo, que visa uma conduta ética orientada moralmente, poderia conter a ganância, a extravagância e a corrupção. Considerada a filosofia ocidental uma filosofia sem alma, Nursi sugeriu análises com base em métodos comparativos que valorizassem distinções alegóricas nas analogias entre a ação humana e os fatores vinculados às crenças espiritualistas. Segundo ele, suas analogias serviriam para revigorar as crenças dos muçulmanos para que confiassem nas verdades do Islã. Assim, o método não se trata apenas de uma ferramenta didática, mas uma abordagem com base no Alcorão.

No próximo capítulo, Sinha discorre sobre o engajamento de Pandita Ramabai Saraswati na educação formal para mulheres. Pertencente a uma alta casta, Ramabai sugeria às mulheres romperem com a ortodoxia religiosa, seja cristã ou islâmica, pois a rigidez imputada inferiorizava o status da mulher indiana e debilitava a vida das crianças quando submetidas ao casamento. Para ela, as mulheres eram vítimas, sujeitos sem agência, vivendo em situações que culminavam na indolência. Seus escritos sobre as observações das sociedades que visitou, principalmente os EUA, passando pelas críticas à escravidão, ao racismo, ao patriarcado, à institucionalização da religião e sobre o status da mulher, visaram propor a emancipação da colonização britânica. Suas investigações usaram história oral, método autobiográfico, pesquisa qualitativa e muitos materiais empíricos. Sinha considera que há uma autorreflexividade intensa da brâmane por elencar fatores estruturais de suas experiências pessoais, principalmente no que diz respeito ao gênero e à ortodoxia religiosa. Para Ramabai, uma análise social é uma précondição para as reformas e, para tanto, é devido considerar as experiências das pessoas.

No nono capítulo, Sinha apresenta Florence Nightingale, pioneira nos estudos estatísticos sobre mortalidade. Muito embora seja mais reconhecida devido a homenagem atribuída à data do seu nascimento, o Dia da Enfermagem, devido à sua atuação. Ficou reconhecida devido à organização de 38 enfermeiras durante a Guerra da 
Criméia, onde não hesitou em produzir relatórios que culminaram em projetos para a saúde pública britânica ${ }^{3}$. Sinha destaca a quantidade expressiva de registros de dados que contribuíram para a medicina preventiva, a promoção da saúde, a reforma sanitária e a arquitetura dos hospitais. Apesar da perspectiva positivista nos seus estudos, típica da formação científica de seu tempo, foi contra a separação da ciência e da religião, pois considerava a espiritualidade imprescindível ao avanço moral. Na sua conduta, o avanço moral se dava com a dedicação aos cuidados, atributo divino de mulheres e que the foi revelado quando tinha 17 anos. Nightingale considerava a enfermagem um exercício profissional para mulheres e uma oportunidade para que estas não se limitassem à ociosidade que o casamento e o resguardo da família as acometiam. Para Nightingale, a noção de cuidado era uma atribuição feminina, mas era com a profissionalização na enfermagem que a conciliação da paixão, do intelecto e da atividade moral promoveria o progresso. Aos 33 anos, assumiu a superintendência de um hospital em Londres.

O último capítulo destaca o indiano Benoy Kumar Sarkar. Suas idéias foram reconhecidas como uma doutrina. Sinha explica como o sarkarismo representou o energismo e o progresso por meio do vínculo do hinduísmo com o positivismo. 0 pragmatismo e o pluralismo do positivismo, para Sarkar, são fundamentos na formação das pessoas sobre seus deveres sociais com base em princípios humanitários. Deste modo, o espiritualismo não se separa do materialismo na Índia. Afirmou que um orientalismo acabou por promover uma divisão pseudo-científica sobre raça, religião e cultura, e proporcionou que os colonizadores instituíssem um padrão universal de medição de mérito. Diante disso, se preocupou com a institucionalização de um currículo que formasse cientistas sociais comfirme consciência sobre a realidade da Índia sob uma perspectiva global e cosmopolita. Diante do respeito ao transcendentalismo e ao espiritualismo, sugere um método histórico para comparar histórias individuais em termos da psicologia, da lógica, da ética, da estética e da metafísica, para afirmar que a civilização hindu faz da espécie humana uma unidade. Assim, defendeu um internacionalismo, contrário aos preconceitos históricos que diferenciaram os humanos, que resguardasse as aspirações individuais e a soberania e a independência das nações.

\footnotetext{
${ }^{3}$ No século XIX, os hospitais foram constituídos profissionalmente de modo a substituir os denominados "morredouros", que eram ambientes administrados pelas igrejas para o alento dos enfermos.
} 
Sinha diz que o sarkarismo é uma postura fuzzy ${ }^{4}$, profética e preditiva, contendo, até mesmo, um "nativismo" quando defende uma política global que preserve um caráter democrático, com atenção aos riscos das práticas despóticas.

Raewyn Connel (2007), ao fazer referência sobre a denominação "teorias do norte" e "teorias do sul", já apontara sobre o problema da hierarquização na produção do conhecimento global. Diferentes violências são disfarçadas. Manter as teorias do norte como canônicas serviram para justificar o imperialismo como um projeto colonizador e instituir a globalização, que nada mais significa a "modernidade" generalizada. Outros escritos nos servem como referência na denúncia da negligência com os intelectuais do "sul global", como do pensador Paulin J. Hountondji (1997), ao tratar de uma sociologia endógena ${ }^{5}$ ou, de modo semelhante, os escritos de Akinsola Akiwowo $(1999)^{6}$, que problematizou sobre uma sociologia indígena. Oyèrónkẹ Oyèwùmí (2011), por exemplo, vai denunciar a violência epistêmica, não somente com a exotização dos estudos em África, mas com a destituição das práticas do povo iorubá por meio de traduções destes intelectuais que, sob perspectivas masculinas da linguagem iorubá, promoveram a destituição da matripotência. Em suma, destacam os aspectos implicitamente colonizatórios na tradução.

Assim, como sugere Glória Anzáldua (2016), a modernidade em sua proposta de conservação de elementos, de entidades, constituindo id-entidades, precisa ser implodida. Tal implosão demanda uma consciência mestiça, representada por sujeitos nas fronteiras. Não se pode deixar de fazer referência, também, à constituição dos denominados estudos culturais e dos estudos subalternos que provocaram, na década de 1980, revisões teóricas, até a associação de um pensamento pós-colonial. De modo geral, há uma denúncia aos as pectos universalistas, ainda que plurais, nas teorias sociais, pois obnubila as hierarquias de raça e gênero, para não dizer dos aspectos de classe. Mas

\footnotetext{
4 O termo fuzzy está associado à lógica binária na programação informática que proporciona, apesar de dual, a constituição de multivalores. Ou seja, há uma difusão de varia das formas a partir de dois valores. ${ }^{5}$ Hountondji (1997) propunha uma produção científica independente da administr ação e controle dos países do Norte, já que há uma escala mundial de acumulação que tem extraído e se apropriado das atividades científicas. Ele analisou os financiamentos estadunidenses, via Fundo Monetário Internacional (FMI), como um projeto neocolonial sob o qual o "turismo intelectual" promoveu uma tradução ocidentalizada da vida africana.

${ }^{6}$ A proposta de Akiwowo era "epistemologizar" o debate inserindo oralidade, espiritualidade e poesia na sociol ogia. Muitos atribuem à sociologia indígena uma etnofil os ofia ou uma lógica fuzzy que incorpora identidades.
} 
é possível uma teoria não universalizante? Pode-se dizer que a sociologia é uma ciência que tende à emergência, pois as experiências são sempre emergentes. Cabe ao teórico em sociologia lidarcom os acoplamentos e as incorporações ainda que, inevitavelmente, imprecisos.

O livro de Alatas e Sinha corresponde a uma alternativa aos estudos em teoria sociológica que não acometa na desconsideração de teorias não-ocidentais. Como afirmam, tal alternativa requer repensar as filosofias, as epistemologias, as histórias e as artes, como fontes potenciais na constituição dos conceitos em ciências sociais, já que "é extremamente raro encontrar um pensador não-ocidental como fonte de teorias e conceitos sociológicos" (tradução livre, ALATAS, SINHA, 2017, p. 7). Isto acaba por delinear um modo de pensar que exclui pensadores em África, na Ásia, por exemplo, que escreveram sobre modernização, como se não existissem. A posicionalidade no pensamento sociológico, assim, visa não acometer uma dependência teórica ocidental, pois sempre houve criação e autonomia. Se há uma perspectiva para a liberdade e a autonomia da agência humana, é preciso que nos desvencilhemos a justificação eurocêntrica sobre a imutabilidade de povos ditos "primitivos", comumente perspectivas consideradas "tradicionais". Esta posicionalidade indica uma potencial episteme, que sempre existiu nessas/es pensadoras/es fronteiriças/os, a garantir a autonomia nas ciências sociais. Ainda é preciso indicar a importância no acionamento das desigualdades de raça, de gênero e de classe para um projeto universalizante em teoria social. Assim, talvez seja possível a constituição de uma sociologia cosmopolita, resultante das interações e conversações transfronteiriças, que funda tradições intelectuais e suas aplicações teóricas. A emergência em sociologia está nas experiências situadas, localizadas, ou seja, nas práticas culturais regionais, locais, que expressam discursos alternativos, fontes potenciais para novos conceitos e teorias em ciência social. Sendo assim, pode-se dizer que o livro de Alatas e Sinha é um convite para tal projeto.

\section{Bibliografia}

AKIWOWO, Akinsola. Indigenous Sociologies: extending the scope of the argument. International Sociology/SAGE, v. 14, n. 115, 1999. 
ALATAS, Syed Farid; SINHA, Vineeta. Sociological Theory Beyond the Canon. Singapura: Palgrave Macmillan, 2017.

ANZALDÚA, Gloria. La conciencia de la mestiza. In: . La Frontera: la nueva mestiza. Madrid: Capitán Swing Libros, 2016.

CONNEL, Raewyn. Southern Theory: the global dynamics of knowledge in social science. Cambridge: Polity Press, 2007.

HOUNTONDJI, Paulin J. Introduction: recentring Africa. In: (Comp.). Endogenous knowledge: research trails. Senegal: CODESRIA, 1997.

OYÈWÙMÍ, Oyèrónkẹ́. Decolonizing the intellectual and the quotidian: Yorùbá Scholars(hip) and Male Dominance. In: - Gender Epistemologies in Africa: gendering traditions, spaces, social institutions, and identities. New York: Palgrave Macmillan, 2011.

QUIJANO, Aníbal. Colonialidade do poder, eurocentrismo e América Latina. In: LANDER, Edgardo (Org.). A colonialidade do saber: eurocentrismo e ciências sociais perspectivas latino-americanas. Colección Sur Sur, CLACSO, Ciudad Autónoma de Buenos Aires, Argentina, 2005. 